\title{
Effect of utilizing unground and ground normal and black rice husk ash on the mechanical and durability properties of high-strength concrete
}

\author{
SYAMSUL BAHRI ${ }^{1,2}, \mathrm{H}^{\text {B MAHMUD }}{ }^{1, *}$ and PAYAM SHAFIGH ${ }^{3}$ \\ ${ }^{1}$ Department of Civil Engineering, Faculty of Engineering, University of Malaya, 50603 Kuala Lumpur, \\ Malaysia \\ ${ }^{2}$ Department of Civil Engineering, Lhokseumawe State Polytechnic, Lhokseumawe, Indonesia \\ ${ }^{3}$ Department of Building Surveying, Faculty of Built Environment, University of Malaya, 50603 Kuala Lumpur, \\ Malaysia \\ e-mail: hilmi@um.edu.my
}

MS received 20 March 2017; revised 15 July 2017; accepted 3 August 2017; published online 10 March 2018

\begin{abstract}
The aim of the present study is to investigate the effects of utilizing different processings of normal rice husk ash (RHA) and black rice husk ash (BRHA) on the mechanical and durability properties of highstrength concrete (HSC). Mechanical and durability properties of HSC were evaluated on concrete mixes containing unground BRHA and RHA and ground BRHA and RHA, their average particles sizes being 165, 85, 67 and $24 \mu \mathrm{m}$, respectively. The replacement of ordinary Portland cement with the ashes was adopted at 20\%. The results showed that incorporating any form of RHA and BRHA in HSC reduced the slump value. The surface areas of RHA and BRHA, not their carbon content, determined the dosage of superplasticizer needed to achieve a targeted slump value. Concrete with unground and ground RHA incorporated exhibited $30 \%$ higher compressive strength while unground BRHA produced $30 \%$ lower compressive strength than that of the control concrete. Incorporating unground and ground RHA showed a synergy between filler and pozzolanic effect and had insignificant difference in mechanical and durability properties of the concretes. Meanwhile, incorporating ground BRHA showed a dominant filler effect in the concrete. Overall, the improvement of splitting tensile strength and modulus of elasticity of both RHA and GBRHA concrete showed a similar trend to that of the compressive strength of RHA concrete. The durability of concretes with unground and ground RHA and ground BRHA incorporated showed better performance than that of the control concrete. The material with $20 \%$ ground BRHA as partial cement replacement in HSC of Grade 50 could be used without any reduction in the mechanical and durability properties. Use of unground BRHA is not recommended because it did not improve these properties.
\end{abstract}

Keywords. Rice husk ash; high-strength concrete; grinding; particle size; durability; low-cost material.

\section{Introduction}

The trend of concrete production nowadays has shifted from normal to high-strength concrete (HSC), which utilizes pozzolanic material to improve strength and durability properties. HSC is defined as a mix having cement content higher than $400 \mathrm{~kg} / \mathrm{m}^{3}$ and its compressive strength at 28 days of greater than $50 \mathrm{MPa}$ [1]. Rice husk ash (RHA) is a pozzolanic material because it contains reactive amorphous silica through a proper combustion process. One of the reasons for increasing research on HSC with RHA incorporated is due to the huge availability of rice husk in paddy growing countries. In 2013, 745 million metric

*For correspondence tonnes of paddy rice was produced annually worldwide [2] and $20 \%$ of that constituted rice husk. Some portions of rice husk are utilized as fuel sources in boiler for generating electricity in rice mill and the rest is dumped and burned in landfills, which can create air pollution. Rice husk has a high content of $\mathrm{SiO}_{2}$ in its outer layer [3]. By properly burning rice husk and grinding the ash, it can be used as a mineral admixture in concrete production [4]. A high quality of RHA can be produced by burning rice husk under controlled temperatures of less than $700^{\circ} \mathrm{C}[5,6]$. This type of RHA has high amorphous silica, low loss on ignition (LOI) and high $\mathrm{SiO}_{2}$ content. Meanwhile, a low-quality RHA, the black rice husk ash (BRHA), is a waste product of agricultural industries as a residue of the cyclonic husk furnace at rice mills. The colour of the residue is black due 
to incomplete combustion of rice husk and mostly has lower amorphous silica, higher LOI and lower $\mathrm{SiO}_{2}$ content than those of normal RHA.

BRHA is normally avoided for use in concrete because it does not satisfy the ASTM C 618 requirements such as LOI content of less than $12 \%$ and combined proportion of silicon dioxide $\left(\mathrm{SiO}_{2}\right)$, aluminium oxide $\left(\mathrm{Al}_{2} \mathrm{O}_{3}\right)$ and iron oxide $\left(\mathrm{Fe}_{2} \mathrm{O}_{3}\right)$ in the ash of greater than $70 \%$. Nair et al [7] suggested that BRHA from residue of paddy parboiling should not be used in producing concrete if its LOI content is greater than $20 \%$ and $\mathrm{SiO}_{2}$ content is lower than $76 \%$. However, some researchers have shown improvement in strength of concrete incorporating BRHA using smaller particle size compared with that of cement and complying with ASTM C 618. Mahmud et al [8] used BRHA and showed that $15 \%$ of BRHA was used as addition to concrete and it gave optimum strength. When it was used as cement replacement, utilizing BRHA as $5 \%$ of total binder could improve mechanical properties. However, Cordiero et al [9] utilized ultrafine BRHA of $3 \mu \mathrm{m}$ particle size with LOI of $11.9 \%$. They reported that $20 \%$ replacement of cement with BRHA produced higher mechanical and durability properties compared with that of control concrete. Rego et al [10] reported that residual RHA with low amorphous silica content proved to be a suitable mineral addition for cements. Chatveera and Lertwattanaruk [11] used ultrafine BRHA with particle size of less than $12 \mu \mathrm{m}$. They reported that the compressive strength and durability properties of concrete were improved when BRHA was used as cement replacement up to $20 \%$. Chopra et al [12] also mentioned that the inclusion of RHA up to $20 \%$ as partial replacement to cement in self-compacted concrete improved the strength and durability properties. Mahmud [13] explained that BRHA with particle size of $12 \mu \mathrm{m}$ could be used to produce HSC of grade 80 , especially at $5 \%$ replacement.

The aim of this study is to investigate the effectiveness of using ground BRHA and RHA on the engineering properties of HSC. The cost of producing RHA will be increased due to the grinding process. Achieving smaller particle size for ashes needs more energy for grinding, and, consequently, more cost is needed. As mentioned earlier, in what most researchers used, the average particle sizes of ashes were less than that of cement. In this study, the average particles of ashes used were coarser than those of previous studies, $3 \mu \mathrm{m}$ [9] and $12 \mu \mathrm{m}[11,13]$. The average particle sizes of unground BRHA and RHA were about 165 and $85 \mu \mathrm{m}$, respectively. In addition, the average particle sizes of ground BRHA and RHA were 67 and $24 \mu \mathrm{m}$, respectively. Ordinary Portland cement (OPC) type I was partially replaced with $20 \%$ of unground or ground RHA and BRHA by mass of cement in concretes. This paper presents chemical and physical properties of BRHA and RHA, compressive strength, splitting tensile strength, modulus of elasticity, permeable porosity and results of rapid chloride permeability test (RCPT). The results of the study would be beneficial to the concrete industry for applications of RHA and BRHA in HSC.

\section{Material and methodology}

\subsection{Materials}

OPC used was of type I conforming to ASTM (CEM 42.5) and its average particle size was $20 \mu \mathrm{m}$. Two types of ashes, BRHA and RHA, and two forms of ashes, unground and ground, were prepared as partial cement replacement. The BRHA (figure 1a) was received from the rice mills in Kuala Selangor, Malaysia, denoted as U-BRHA. Meanwhile, RHA (figure 1b) was produced from combustion in a ferrocement furnace in the laboratory with peak temperature below $700^{\circ} \mathrm{C}$ and denoted as U-RHA. When rice husk is heated from 100 to $600^{\circ} \mathrm{C}$, the organic matter like cellulose, lignin, etc. decomposes into carbon [14]. From figure 1, it can be seen that the colour of BRHA and RHA is black and grey, respectively. The black colour of BRHA is due to incomplete combustion of rice husk [15]. The BRHA and RHA were ground using a Los Angeles (LA) machine using 40 steel bars of $10.5 \mathrm{~kg}$ as abrasive weight and a rotating drum for 30,000 cycles lasting $16 \mathrm{~h}$. The average particle size of the U-BRHA was $165 \mu \mathrm{m}$, and after grinding the average particle size of BRHA was $67 \mu \mathrm{m}$, denoted as G-BRHA (figure 1c). The average particle size of the U-RHA was about $85 \mu \mathrm{m}$. After grinding, the average particle size of RHA was $24 \mu \mathrm{m}$, denoted as G-RHA (figure 1d). The average particle sizes of the G-BRHA were larger than that of the G-RHA even after following a similar grinding method.

The chemical characteristics of BRHA, RHA and OPC were obtained by XRF and LOI analysis. Chemical compositions of cement and the two types of RHA are presented in table 1. The chemical compositions of ground RHA and BRHA are not provided in this paper. There are no significant variations in chemical compositions of the ashes before and after they are ground [16]. It can be seen in this table that $\mathrm{SiO}_{2}$ content of BRHA and RHA is $63.17 \%$ and $85.76 \%$, respectively. LOI percentages of BRHA and RHA are $12.8 \%$ and $4.05 \%$, respectively. Based on ASTM C 618, unground RHA can be classified as a pozzolanic material, as its silica content is greater than $65 \%$ and LOI content is lower than $12 \%$.

The amorphousness of silica in U-BRHA and U-RHA was checked through X-ray diffraction (XRD) analysis. The XRD data were obtained using a PanAlyticalX'Pert diffractometer, operating with $\mathrm{Cu}$ radiation $(\mathrm{CuK} \alpha=1.54060 \AA)$ and generator settings at $40 \mathrm{~mA}$, $45 \mathrm{kV}$. The scanning speed was $20 \% \mathrm{~min}$ in a $2 \theta$ range from $50^{\circ}$ to $800^{\circ}$. The XRD of U-BRHA and U-RHA in figure 2 shows that the diffractogram of those ashes has a broad hump centred around a $2 \theta$ angle of $22^{\circ}$, indicating that both ashes are amorphous. The crystalline silica on U-BRHA 

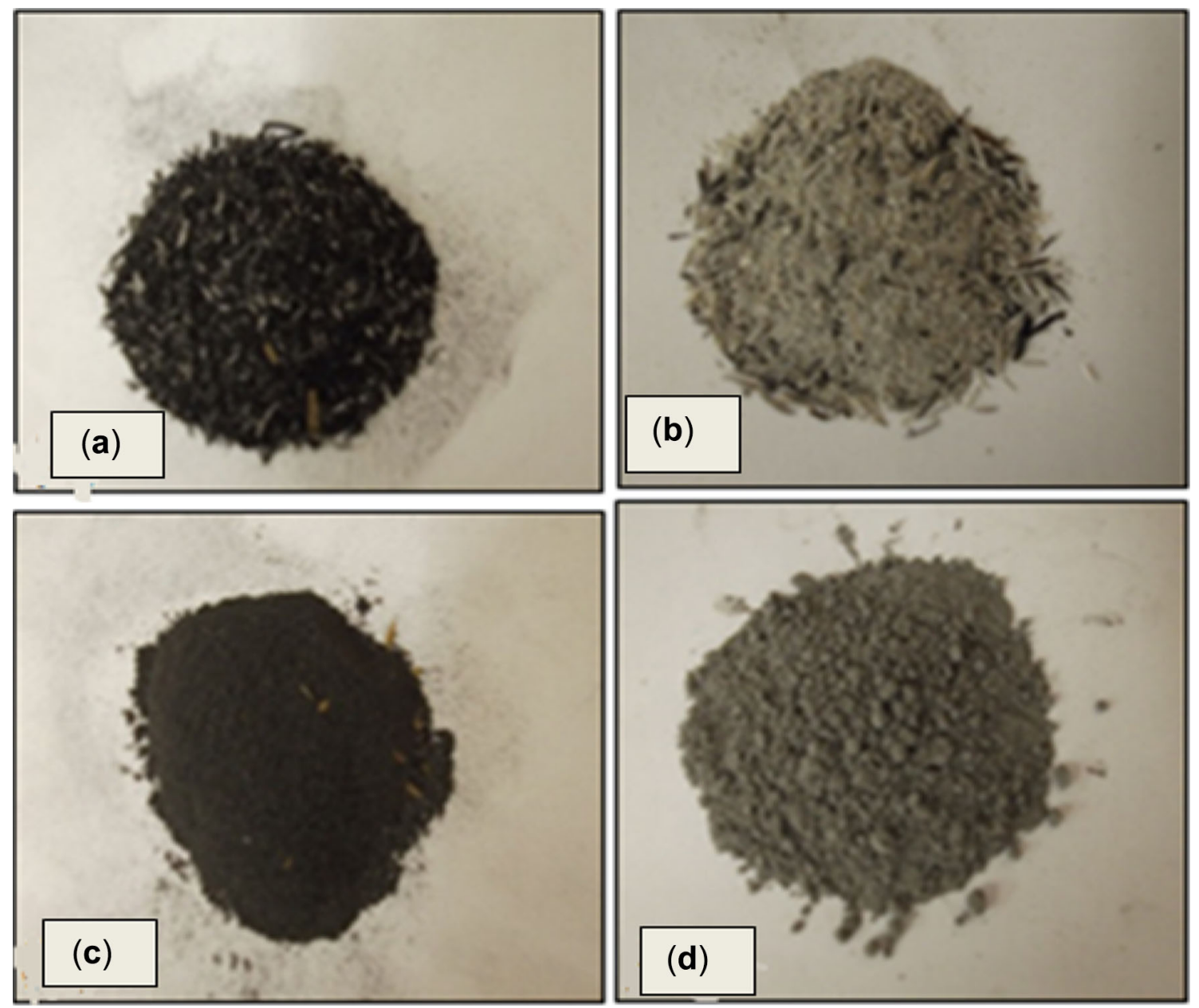

Figure 1. (a) U-BRHA, (b) U-RHA, (c) G-BRHA and (d) G-RHA.

Table 1. Chemical properties of OPC, U-BRHA and U-RHA.

\begin{tabular}{lrrr}
\hline Chemical composition $(\%)$ & OPC & U-BRHA & U-RHA \\
\hline Magnesium oxide $(\mathrm{MgO})$ & 2.06 & 5.96 & 0.81 \\
Aluminium oxide $\left(\mathrm{Al}_{2} \mathrm{O}_{3}\right)$ & 5.60 & 3.26 & 0.25 \\
Silicon dioxide $\left(\mathrm{SiO}_{2}\right)$ & 21.28 & 63.17 & 85.76 \\
Sulphate $\left(\mathrm{SO}_{3}\right)$ & 2.14 & 1.14 & 0.31 \\
Calcium oxide $(\mathrm{CaO})$ & 64.64 & 7.78 & 0.74 \\
Iron oxide $\left(\mathrm{Fe}_{2} \mathrm{O}_{3}\right)$ & 3.38 & 0.05 & 1.15 \\
Loss on ignition $(\mathrm{LOI})$ & 0.60 & 12.80 & 4.05 \\
\hline
\end{tabular}

was possible due to the impurities of the ashes. It was collected from an open discharge in the rice mill yard, which may be subjected to some minor contamination from soil ground. Chopra et al [17] also reported that the silica was predominantly in amorphous form for incineration temperatures up to $700^{\circ} \mathrm{C}$ and some cristobalite existed in RHA if the combustion exceeded.

The BET specific surface area was measured using a nitrogen absorption apparatus (MicroActive 2.00-TriStar II

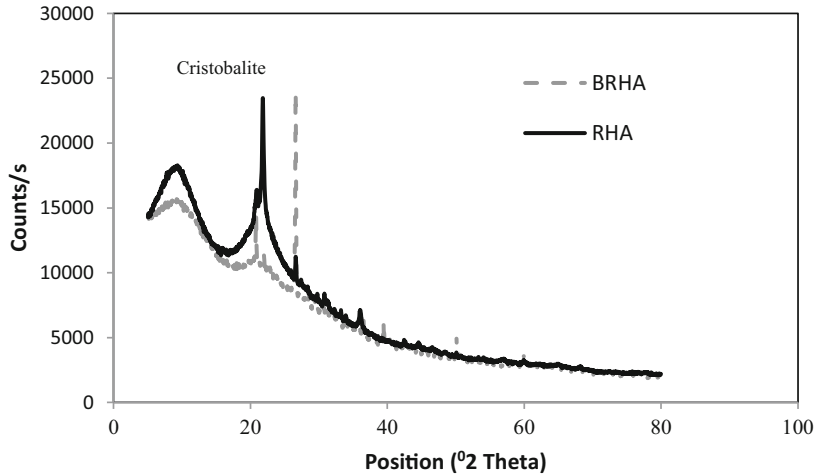

Figure 2. The XRD of (a) BRHA and (b) RHA.

3020 V1.04). The particle size distributions of BRHA, RHA and OPC were measured using a laser diffraction particle size analyser (Mastersizer S standard Bench Malvern instrument) using the dry method.

Fine and coarse aggregates used were mining sand and crushed granite with a maximum grain size of 4.75 and 
$19 \mathrm{~mm}$, respectively. The specific gravity of the fine and coarse aggregate was 2.84 and 2.66 , respectively.

Pipe water that was free from contamination was used in all the mixes. The type of superplasticizer used was polycarboxylate ether (PCE) with $40 \%$ solid content by mass and was supplied by BASF Sdn. Bhd.

\subsection{Mix proportions of concrete mixes}

Table 2 shows the mix proportions of concrete mixes incorporating unground and ground ashes for BRHA and RHA. The control concrete was designed to achieve compressive strength of $50 \mathrm{MPa}$ at 28 days based on the BRE mix design method [18]. Slump values for all the mixes were designed in the range of 100-110 mm. The mixtures contained constant water/binder $(w / b)$ ratio of 0.46 and total binder content of $457 \mathrm{~kg} / \mathrm{m}^{3}$. The percentage of cement replacement by ash was $20 \%$ [11].

\subsection{Experimental procedures}

The workability of the fresh concretes was measured using a slump test based on BS 1881-102. The slump test was conducted directly before fresh concrete was placed into the moulds. After placement, the specimens were covered with polyethylene sheet to prevent water evaporation. The concrete moulds were dismantled after $24 \mathrm{~h}$ and the specimens were placed in a water curing tank. Concrete cubes of $100 \times 100 \times 100 \mathrm{~mm}^{3}$ were casted for compressive strength test based on BS 1881-116. For splitting tensile strength and modulus of elasticity, concrete cylinders of $100 \mathrm{~mm} \times 200 \mathrm{~mm}$ and $150 \times 300 \mathrm{~mm}^{2}$ dimensions were used based on BS 1881-117 and BS 1881-12, respectively. The permeable porosity was measured as suggested by Safiuddin and Hearn [19] and the specimens were prepared using the vacuum saturation instead of cold-water or boiling-water saturation techniques. The permeable porosity of concrete was calculated based on the concept of weight gain due to permeable porosity and weight loss because of buoyancy. The following equation [Eq. (1)] was used to calculate the permeable porosity of concrete:

$$
\text { permeable porosity }=\frac{W_{s}-W_{d}}{W_{s}-W_{b}} \times 100 \%
$$

where $W_{b}$ is the buoyant mass of the saturated specimen in water, $W_{d}$ is the oven-dry mass of the specimen in air and $W_{s}$ is the saturated surface-dry mass of the specimen in air.

RCPT was conducted in accordance with ASTM C 1202-97. Concrete cylinders of 100 diameter $\times 50 \mathrm{~mm}$ height were used for RCPT. Figure 3 shows the test set-up for RCPT. The compressive strength of concrete was determined at 1, 3, 7, 28 and 56 days. Meanwhile, the splitting tensile strength of concrete and RCP value were determined at 3, 7, 28 and 56 days. The modulus of elasticity of concrete was determined at 7 and 28 days.

\section{Results and discussion}

\subsection{Effect of grinding on the physical properties of $R H A$}

Table 3 shows some physical properties of OPC, BRHA and RHA. The average particle size of G-RHA is closest to that of OPC; $10 \%$ particle sizes of the G-BRHA, U-RHA and G-RHA are lower than the average particle size of OPC. Higher concentration of smaller particles in the cementitious materials will cause higher pozzolanic reaction [20].

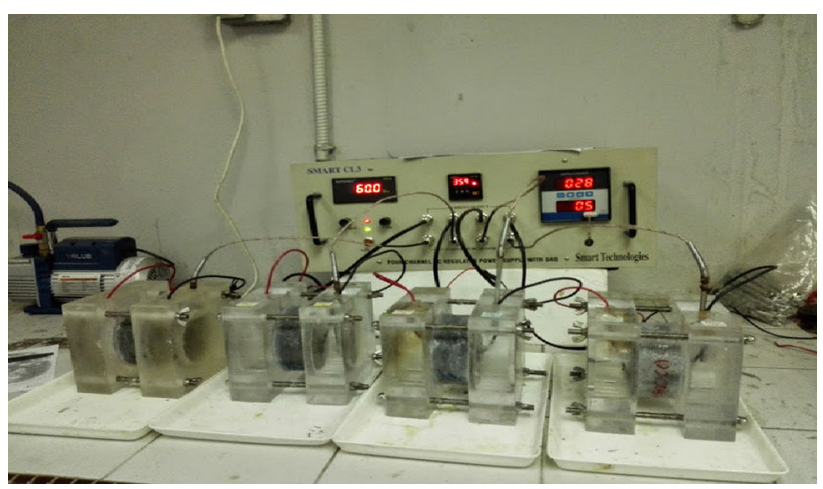

Figure 3. Rapid chloride permeability test.

Table 2. Mix proportions of HSC $\left(\mathrm{kg} / \mathrm{m}^{3}\right)$.

\begin{tabular}{|c|c|c|c|c|c|c|c|c|c|}
\hline Mix ID & OPC & U-BRHA & G-BRHA & U-RHA & G-BRHA & Coarse agg. & Fine agg. & Water & $\mathrm{Sp}^{*}$ \\
\hline Control & 457 & 0.0 & 0.0 & 0.0 & 0.0 & 948 & 745 & 210 & $\overline{0.0}$ \\
\hline U-BRHA & 365 & 92 & 0 & 0 & 0 & 948 & 745 & 210 & 1.2 \\
\hline G-BRHA & 365 & 0.0 & 92 & 0 & 0 & 948 & 745 & 210 & 1.5 \\
\hline U-RHA & 365 & 0 & 0.0 & 92 & 0 & 948 & 745 & 210 & 2.6 \\
\hline G-RHA & 365 & 0 & 0.0 & 0 & 92 & 948 & 745 & 210 & 2.1 \\
\hline
\end{tabular}

*\% of binder and the $\mathrm{Sp}$ is specified as the solid mass. 
Table 3. Physical properties of OPC, BRHA and RHA.

\begin{tabular}{|c|c|c|c|c|c|}
\hline Properties & $\mathrm{OPC}$ & U-BRHA & G-BRHA & U-RHA & G-RHA \\
\hline Specific mass $\left(\mathrm{g} / \mathrm{cm}^{3}\right)$ & 3.15 & 1.92 & 1.98 & 2.06 & 2.16 \\
\hline Average particle diameter $(\mu \mathrm{m})$ & 20.085 & 164.738 & 66.297 & 84.382 & 23.960 \\
\hline Maximum particle diameter below $10 \%$ of particle $(\mu \mathrm{m})$ & 3.424 & 40.395 & 15.449 & 13.956 & 4.146 \\
\hline BET specific surface area $\left(\mathrm{m}^{2} / \mathrm{g}\right)$ & 1.060 & 11.254 & 19.812 & 76.195 & 40.888 \\
\hline Pore volume $\left(\mathrm{cm}^{3} / \mathrm{g}\right)$ & 0.004 & 0.014 & 0.009 & 0.160 & 0.058 \\
\hline
\end{tabular}
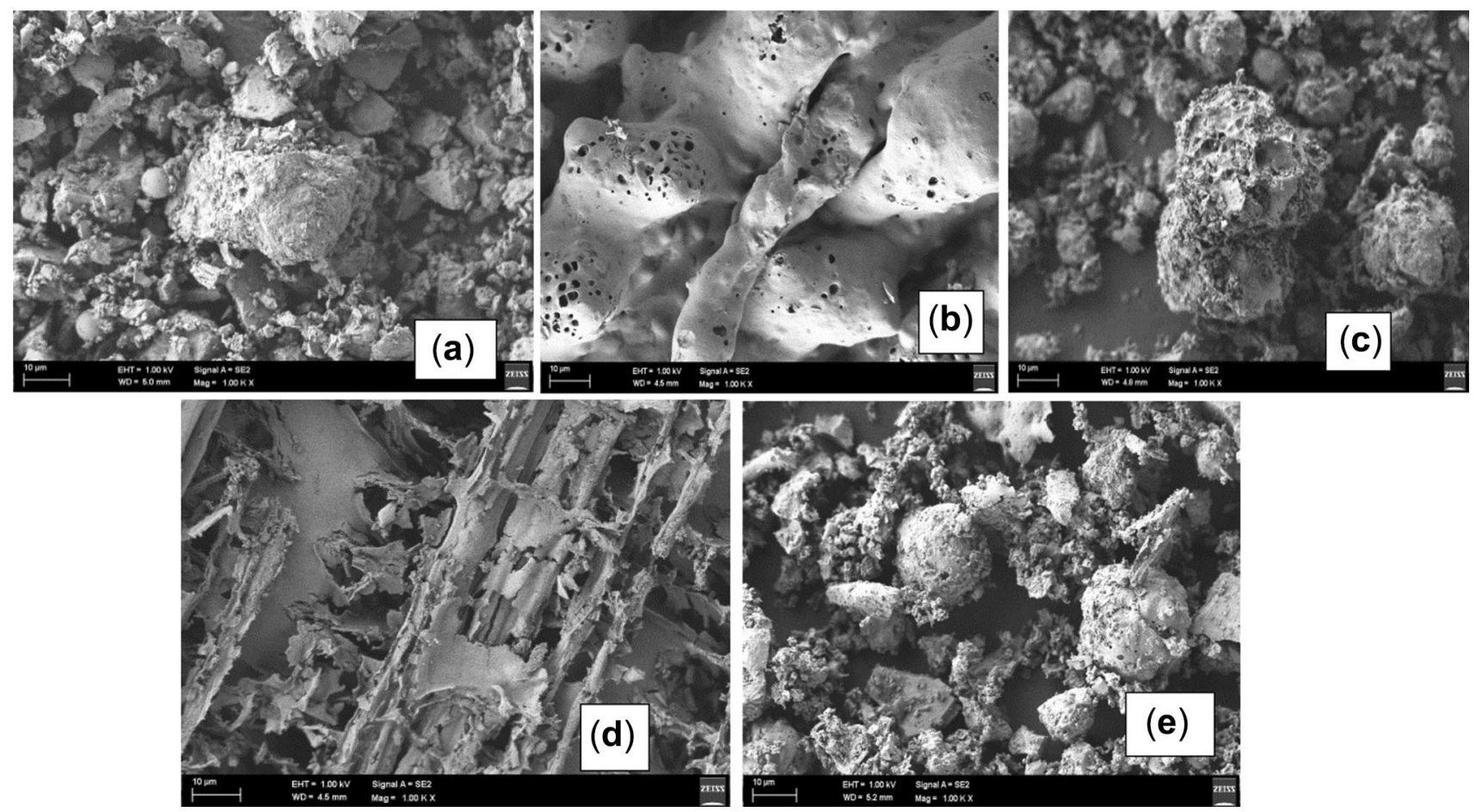

Figure 4. Particles in $1.00 \mathrm{k}$ magnification: (a) cement, (b) U-BRHA, (c) G-BRHA, (d) U-RHA and (e) G-RHA.

Figure 4 shows the microscopic images of BRHA, RHA and OPC. As can be seen in these figures, the BRHA and RHA grains have porosities while the OPC grains do not have any porosity. FSEM images revealed that RHA is microporous and irregular (figure $4 \mathrm{~b}-\mathrm{e}$ ). The average particle size of the U-RHA is bigger than that of the G-BRHA but the surface area of the U-RHA is higher than that of the G-RHA. As RHA is a porous material, grinding the U-RHA broke the inner pores and reduced both pore volume and its particle size to $64 \%$ and $71 \%$, respectively, and the surface area of the G-RHA was reduced to $50 \%$ of that of the U-RHA. However, BRHA is less porous compared with RHA and grinding the U-BRHA increases the surface area of the G-BRHA to 50\% higher than that of the U-BRHA. The surface areas of all types of BRHA and RHA are higher than that of OPC. Figure 5 shows that the fine particles fill in the porous RHA. A similar observation is reported by Cordeiro et al [9], stating that grinding process collapsed the cellular structure of RHA and some fine particles filled the initial pores, resulting in less pores. Habeeb and Mahmud [21] mentioned that the surface area of RHA was not only controlled by average particle sizes but also from the RHA's multi-layered, angular and microporous surface.

Figure 6a shows the particle size distributions of cement, BRHA and RHA. The ashes are produced under similar grinding processes but the G-BRHA and the G-RHA have different average particle sizes, which are 66.3 and $24.0 \mu \mathrm{m}$, respectively. These particle sizes were achieved under an optimum grinding time for the G-BRHA and the G-RHA and beyond that a further reduction of particle size required high energy consumption. The difficulty of grinding fine particles is related to their high strength, low capture probability and tendency to agglomerate [9]. Figure $6 \mathrm{~b}$ shows that the fine particles portrayed a unimodal particle size distribution while the coarse ones showed a bimodal distribution. The unimodal distribution 


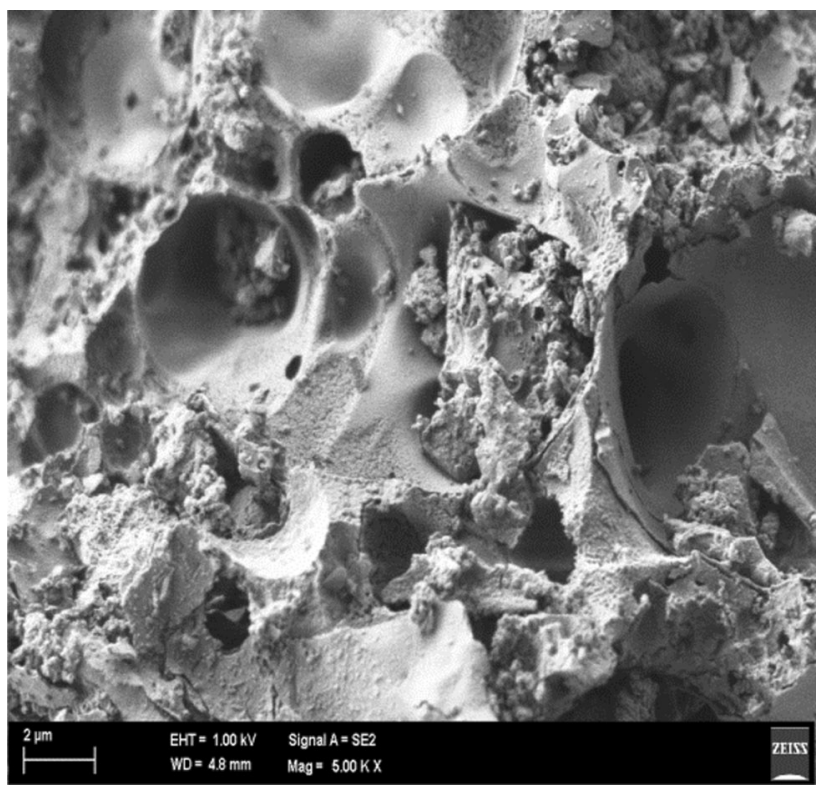

Figure 5. Smaller particles fill the pores.

corresponds to the homogeneity of ashes whereas the bimodal distribution showed their heterogeneous nature [22].

\subsection{Workability of fresh concrete}

Table 2 shows the dosage of superplasticizer ( $\mathrm{Sp}$ ) used in each mix proportion. In the case of control concrete, it did not require any $\mathrm{Sp}$ since its $w / b$ ratio was greater than 0.42 . When $w / c$ ratio of OPC concrete is 0.42 , all the pores within the system are completely filled with water throughout the hydration reaction [23]; then the mixing water is sufficient for workability of fresh concrete. The workability of a concrete mix is provided by the paste, which fills the voids between aggregates. The paste acts as a lubricant that reduces internal friction between aggregates while increasing workability [24]. However, RHA concrete needed a certain amount of dosage $\mathrm{Sp}$ to achieve similar workability to that of fresh control concrete. As can be seen in table 3, BRHA and RHA have higher surface areas and therefore need more water to wet the surface. Therefore, the available mixing water was reduced and it affected the workability of fresh BRHA and RHA concrete. Thus, only mixtures containing BRHA and RHA required additional dosage $\mathrm{Sp}$ to achieve the targeted slump value. The G-BRHA mix needed $25 \%$ extra $\mathrm{Sp}$ than that of the U-BRHA mix. However, the G-RHA mix used 24\% less dosage Sp than that of the U-RHA mix to maintain similar workability. A similar result was also found by Rego et al [10], indicating that incorporating BRHA and RHA in concrete mixtures reduced the slump value of fresh concrete and the amount of superplasticizer needed was higher to get similar slump to that of fresh control concrete.

Figure 7 shows that there is a logarithmic relationship with strong correlation between specific surface area and dosage of superplasticizer needed. The higher the surface area of BRHA and RHA, the higher the $\mathrm{Sp}$ needed, regardless of the LOI content. This result is in agreement with other researchers [25], who concluded that the increasing dosage Sp needed in RHA concrete mixtures was related to the surface area of RHA. However, Cordeiro et al [9] and Sua-iam and Makul [26] reported that decreasing slump value of RHA concrete was due to the high specific surface area and also the high unburned carbon content of the RHA. The addition of superplasticizer in RHA concrete, which is flocculated by cement particles, is

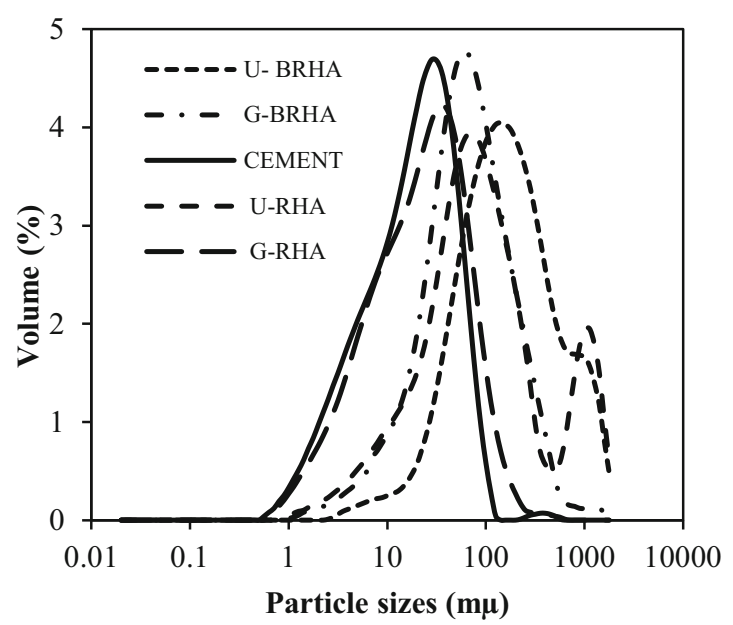

(b)

Figure 6. The particle size distributions of the cementitious materials (a) based on cumulative passing and (b) based on volume. 


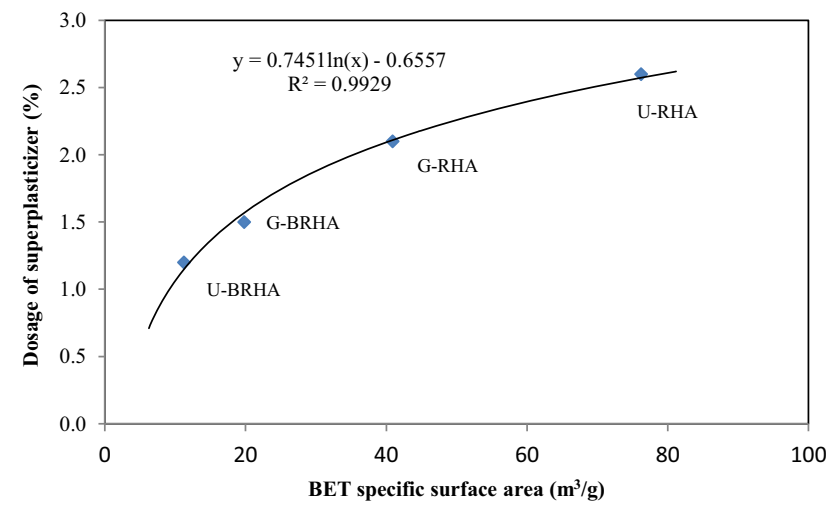

Figure 7. Relationship between specific surface area and dosage of superplasticizer needed for similar workability.

important for releasing water and, therefore, the released water could lubricate the mixture and create less friction among the concrete ingredients. It should be noted that it is very important in RHA concrete production to achieve good workability to ensure appropriate dispersion of the fine particles and their proper migration into the interface transition zone (ITZ) of concrete [27].

\subsection{Compressive strength}

Figure 8 shows the compressive strength of BRHA and RHA concretes relative to that of control concrete up to 56 days. The 1-day strength of the U-RHA, G-RHA, G-BRHA and U-BRHA concretes was 94\%, 107\%, $117 \%$ and $60 \%$ of control concrete or 17.4, 19.9, 21.8 and 11.1 $\mathrm{MPa}$, respectively. It is an interesting phenomenon that concrete containing G-BRHA exhibited higher compressive strength at early age compared with that of concrete containing RHA, which has lower LOI and high silica content. The improvement in strength that occurred in the G-BRHA concrete at early age could be because $10 \%$ particle sizes of the G-BRHA are below the average particle size of cement. It could fill the void in cement paste and ITZ, which subsequently make the concrete denser.

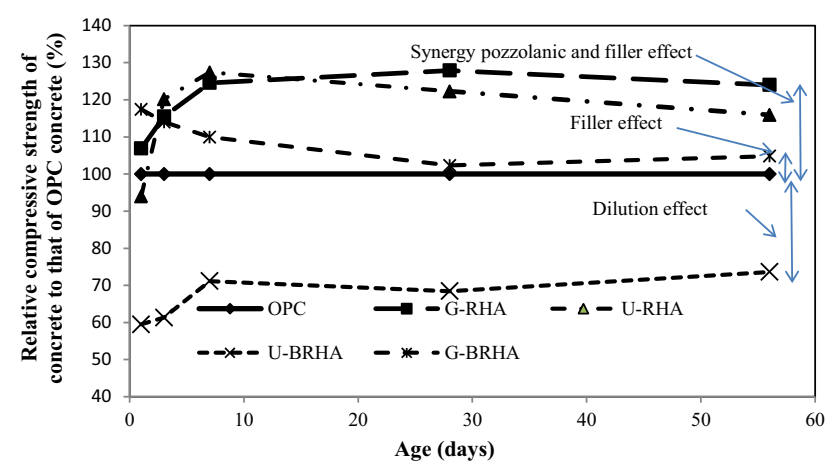

Figure 8. Relative compressive strength of BRHA and RHA concrete to that of control concrete.
Tangapasit et al [28] reported that the finer particle size of pozzolan material could improve the packing effect of the material. However, the compressive strengths of U-RHA concrete at early age are lower than those of the control and G-RHA concrete. This could be because pores of U-RHA absorb the superplasticizer, which could retard the hydration of cement through the formation of a coating film around hydrated products [29]. The delayed setting time of the paste significantly affected the mechanical properties at early ages [30]. As mentioned earlier, the unground RHA needed more superplasticizer than the ground RHA so that the excessive dosage $\mathrm{Sp}$ in U-RHA affected its early compressive strength. However, in the case of the U-BRHA, its compressive strength is lower than that of control concrete and it is possible that $10 \%$ particle size of the U-BRHA is above the average particle size of cement, and it does not fill in the ITZ of concrete and thus does not improve the packing density of ITZ. Scrivener et al [31] pointed out that the particle size of supplementary cementitious material should be less than the particle size of cement in order to improve ITZ of concrete.

Contrary to the compressive strength of concrete at the early ages, at the end of 28 days and onwards the reaction of concrete incorporating the G-RHA and U-RHA increased compared with that of the G-BRHA, U-BRHA and control concrete. From figure 8 , it can be seen that the U-RHA and G-RHA concrete exhibited significant improvement in compressive strength at later ages. It also shows that the effect of retardation on compressive strength of the G-RHA concrete is present only at early ages. The 28-day compressive strengths of the U-RHA, G-RHA, G-BRHA and U-BRHA were $122 \%, 128 \%, 102 \%$ and $68 \%$ of control concrete or $64.7,67.7,54.1$ and $36.2 \mathrm{MPa}$, respectively. The significant improvement in the U-RHA and G-RHA could be related to the pozzolanic reaction of RHA with $\mathrm{Ca}(\mathrm{OH})_{2}$, which was released from hydration of cement. Therefore, more calcium silicate hydrate (CSH) was produced. This product was deposited in the pore system, making the cement paste more homogeneous and denser than the control concrete [32].

The increase in compressive strength of the U-RHA and G-RHA confirms the synergy of filler and pozzolanic effect. In the case of the G-BRHA concrete, the rate of compressive strength gain was decreased, which confirms that the pozzolanic reaction was less. However, the compressive strength of the G-BRHA concrete was still higher than that of the control concrete. As can be seen in table 3, although the average particle size of the G-BRHA is three times higher than that of OPC, its $10 \%$ particle size was below the average particle size of cement. Its compressive strength gains could be due to the filler effect. Meanwhile, the strength of the U-BRHA concrete was $75 \%$ of that of the control concrete, which meant that the U-BRHA concrete experienced dilution effect since early age. The U-BRHA has low-reactivity pozzolan and high LOI content, and its particle size is bigger than that of cement. An inert material 
having porous structures provides weaker areas in the hardened matrix [33]. The large particle size of SCM could weaken the microstructure [34] and could have negative effect on the concrete.

This information is very useful to the concrete industries, where they can choose the type of RHA and processing to be used to produce concrete of Grade 50. The use of the G-RHA and U-RHA in HSC is recommended, but this increases the cost of concrete production because the rice husk has to be burned at controlled temperature in the range of $600-700^{\circ} \mathrm{C}$. As an alternative, the G-BRHA, which does not require specific treatment, could be used as partial cement replacement for HSC of Grade 50.

\subsection{Splitting tensile strength}

Figure 9 shows the relative splitting tensile strength of BRHA and RHA concrete to that of control concrete. The splitting tensile strength of concrete incorporating the U-RHA and G-BRHA improved since the early age. Concrete incorporating G-BRHA showed improvement after 7 days; however, concrete incorporating the U-BRHA showed lower tensile strength than that of control concrete. The splitting tensile strength of the U-RHA, G-RHA, G-BRHA and U-BRHA concrete was 122\%, 136\%, $118 \%$ and $85 \%$ of that of the control concrete at 28 days or 4.6, 5.1, 4.4 and 3.2 $\mathrm{MPa}$, respectively.

The increasing trend of splitting tensile strength of BRHA and RHA concretes is similar to that of compressive strength development. It can be seen from figure 9 that the rate of tensile strength gain of the U-RHA concrete decreased before 7 days and the G-RHA concrete increased after 7 days. It shows that the pozzolanic reaction is continuous. Decreasing rate of strength was the result of lack of calcium hydroxide $(\mathrm{CH})$. Increasing rate of strength gain means that large amount of $\mathrm{CH}$ was available, which could react with $\mathrm{SiO}_{2}$ and produced $\mathrm{CSH}$ and therefore the bond strength increased. However, improvement in the splitting tensile strength could also be due to the increased bond

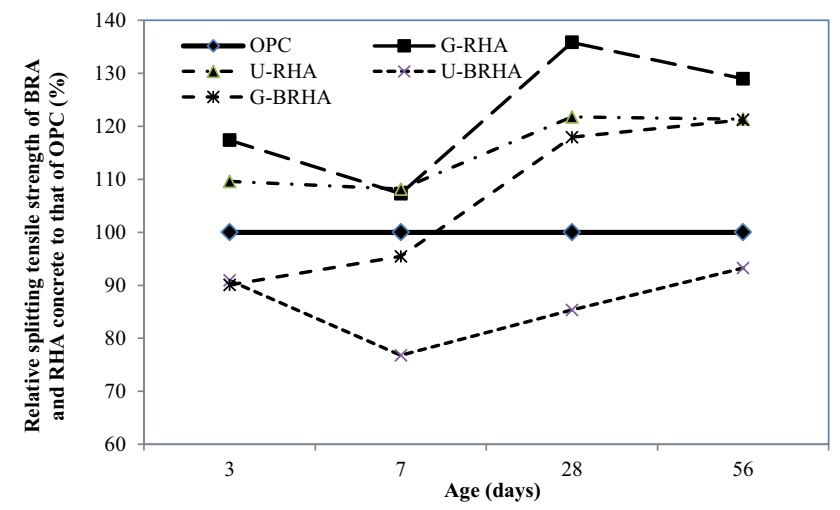

Figure 9. Relative splitting tensile strength of BRA and RHA concrete to that of OPC $(\%)$. strength. The G-BRHA concrete showed higher compressive strength at early age but had less tensile strength than that of control concrete. The increase in the rate of strength gain of the G-BRHA concrete after 7 days showed that the G-BRHA has an amount of reactive amorphous silica even though its existing average particles were $70 \mu \mathrm{m}$. It was reported $[35,36]$ that RHA particles size in the range of 10-75 $\mu \mathrm{m}$ had satisfactory pozzolanic behaviour. The G-BRHA was less reactive due to its higher LOI content and lower $\mathrm{SiO}_{2}$ content compared with those of RHA. In the case of the U-BRHA concrete, its splitting tensile strength was lower and it could be due to poor bonding in the matrix [32] and also the U-BRHA produced the weakest points in the hardened matrix due to its porous structure [33]. However, even though its improvements in strength were lower than that of control concrete, after 7 days the strength of the U-BRHA increased with increasing age, which indicated a slow pozzolanic reaction.

\subsection{Modulus of elasticity}

Figure 10 shows the result of the modulus of elasticity of various RHA concretes. All concretes showed a similar trend in the development of the modulus of elasticity, except for the U-BRHA concrete. The modulus of elasticity of the U-BRHA concrete is lower than that of control concrete and this trend is consistent with the development of the compressive and splitting tensile strength of these concretes. At 28 and 56 days, the difference in modulus of elasticity of control concrete with that of RHA and the G-BRHA concrete is only $5 \%$, which is insignificant. It can be concluded that BRHA and RHA do not have significant influence on the modulus of elasticity. Since compressive strengths (at 28 days) of these concretes vary from 45 to $60 \mathrm{MPa}$, they can be referred to as HSC. Thus, the modulus of elasticity can be predicted using the equation from ACI 318-95 for HSC.

ACI 318-95 [37] suggests Eq. (2) to relate elastic modulus and compressive strength of concrete:

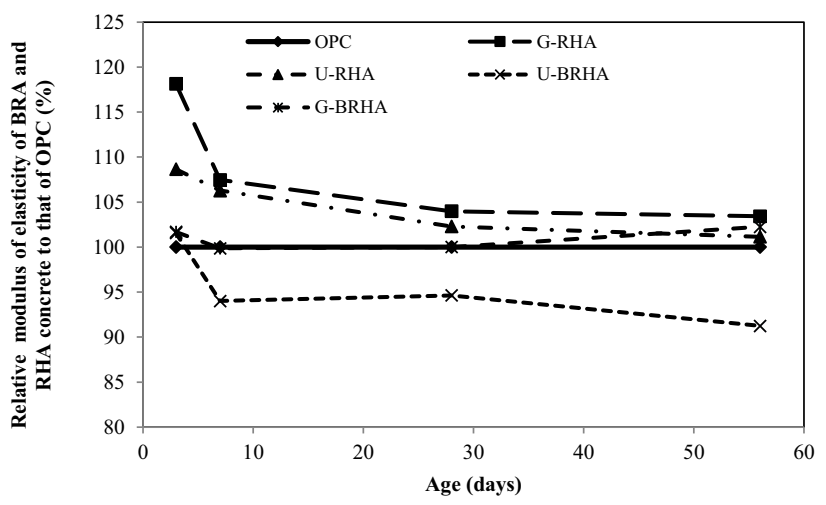

Figure 10. Development of modulus elasticity of HSC. 
Table 4. Predicted and measured modulus of elasticity of concrete.

\begin{tabular}{|c|c|c|c|c|c|}
\hline $\begin{array}{l}\text { Type of } \\
\text { concrete }\end{array}$ & $\begin{array}{l}\text { Age } \\
\text { (days) }\end{array}$ & $\begin{array}{c}\text { Equivalent cylinder } \\
\text { compressive strength }(\mathrm{MPa})\end{array}$ & $\begin{array}{l}\text { Measured modulus of } \\
\text { elasticity }(\mathrm{GPa})\end{array}$ & $\begin{array}{l}\text { Predicted modulus of elasticity } \\
\text { from Eq. (2) (GPa) }\end{array}$ & $\begin{array}{l}\text { Measured } E_{c} / \\
\text { predicted } E_{c}\end{array}$ \\
\hline \multirow[t]{2}{*}{ OPC } & 7 days & 35.2 & 28.6 & 27.9 & 0.97 \\
\hline & 28 days & 47.6 & 32.1 & 32.4 & 1.01 \\
\hline \multirow[t]{2}{*}{ U-BRHA } & 7 days & 25.0 & 26.9 & 23.5 & 0.87 \\
\hline & 28 days & 32.6 & 30.4 & 26.8 & 0.88 \\
\hline \multirow[t]{2}{*}{ G-BRHA } & 7 days & 38.7 & 28.6 & 29.2 & 1.02 \\
\hline & 28 days & 48.7 & 32.1 & 32.8 & 1.02 \\
\hline \multirow[t]{2}{*}{ U-RHA } & 7 days & 43.8 & 30.4 & 31.5 & 1.01 \\
\hline & 28 days & 58.2 & 32.8 & 35.9 & 1.09 \\
\hline \multirow[t]{2}{*}{ G-RHA } & 7 days & 44.8 & 31.1 & 31.1 & 1.02 \\
\hline & 28 days & 60.9 & 33.4 & 36.7 & 1.10 \\
\hline
\end{tabular}

*A factor of 0.9 was used to convert cube to cylinder compressive strength.

$$
E_{c}=4.73\left(f_{c}\right)^{1 / 2}
$$

where $f_{c}$ is the compressive strength of standard cylinder specimen and $E_{c}$ is the modulus of elasticity. As can be seen in table 4, except for concrete containing the U-BRHA, Eq. (2) can give a close estimation compared to the experimental values. It should be noted that the value of the modulus of elasticity is an important parameter in designing a structure with regard to deformation.

\subsection{Permeable porosity}

Figure 11 shows the changes of permeable porosity in control concrete and concretes incorporating RHA and BRHA at different ages. The G-RHA concrete had the lowest permeable porosities at all ages for 7 and 56 days and its permeable porosity was $4.8 \%$ and $2.7 \%$, respectively; this value for control concrete was $5.7 \%$ and $4.1 \%$, respectively. The highest permeable porosity was exhibited by U-BRHA concrete, which was $5.7 \%$ and $4.6 \%$, respectively. The lower permeable porosity for the G-RHA, U-RHA and G-BRHA concretes is believed to be due to the hydration process, pozzolanic reaction and filler effect of RHA.

Grinding of BRHA and RHA increased their surface areas, which improved the capability of $\mathrm{SiO}_{2}$ of BRHA and RHA to react with $\mathrm{CaOH}$ from cement hydration. As can be seen in figure 11, permeable porosity of the G-BRHA concrete is lower than that of control concrete. This shows that grinding, as mechanical treatment for low-quality RHA, significantly improved its performance in permeable porosity of concrete when compared with the U-BRHA. In the case of the U-RHA and G-RHA, the filler effect and pozzolanic effect synergize each other and reduce the porosity [38]. This resulted in their permeable porosity being lower than that of the BRHA concrete. Most good concretes have permeable porosity below $10 \%$ of its mass [39]. The present concretes have permeable porosity of less

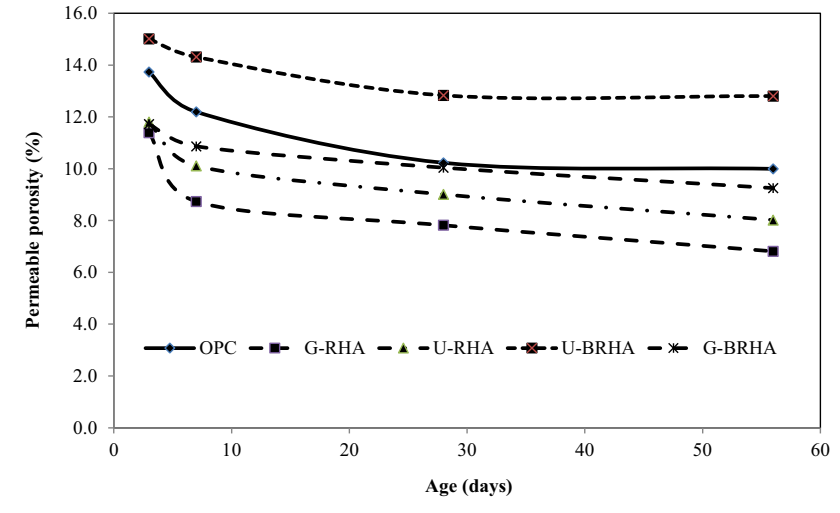

Figure 11. Permeable porosity of HSC incorporating RHA and BRHA.

than $10 \%$ and from the permeable porosity point of view, the G-BRHA concrete can be used as HSC of Grade 50.

Figure 12 shows the relationship between permeable porosity and compressive strength of concrete with good correlation. The figure clearly shows that improvement of

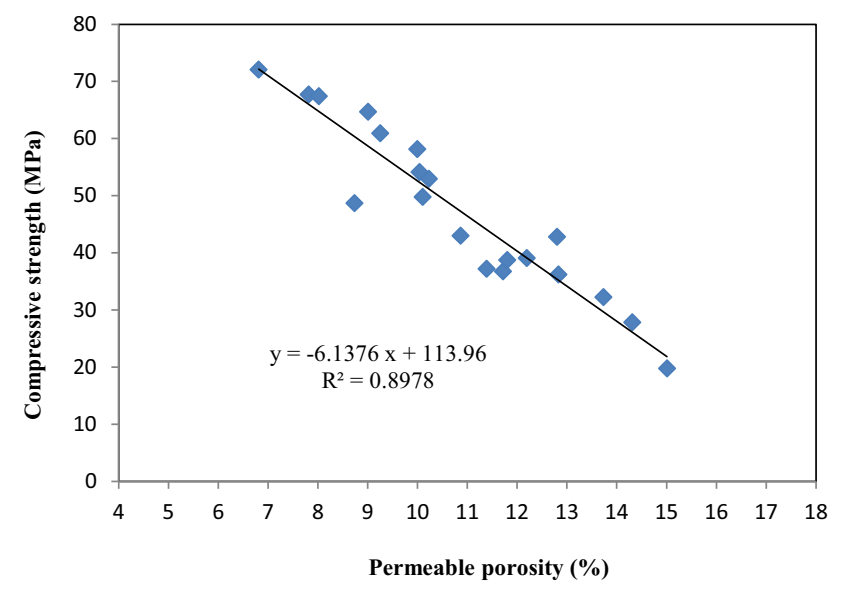

Figure 12. Relationship between permeable porosity and compressive strength of concrete. 


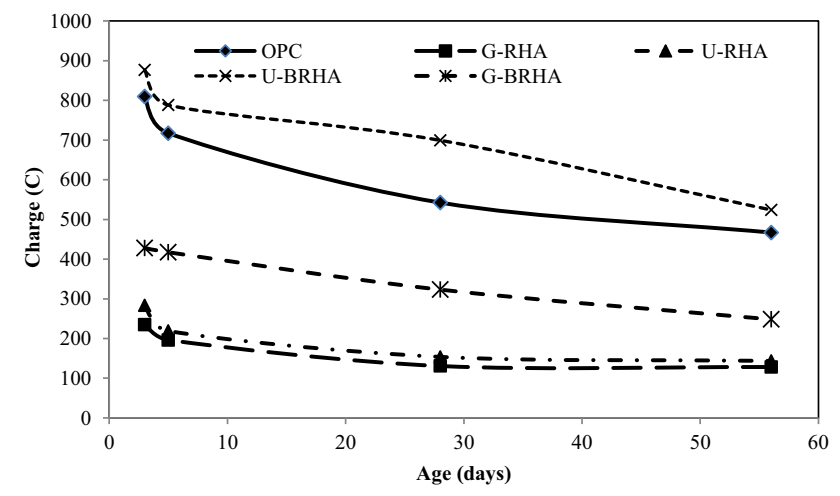

Figure 13. The RCP values of various BRHA and RHA concretes.

compressive strength is related to the reduction in permeable porosity. A strong correlation of $R^{2}=0.8978$ between the two parameters was achieved.

\subsection{Rapid chloride permeability}

According to ASTM C 1202, concrete having chloride ion penetrability value in the range of $100-1000^{\circ} \mathrm{C}$ is categorized as having very low ion penetration. As shown in figure 13, all concretes have RCP values of less than 1000 $\mathrm{C}$ and it indicates that all concretes have the capability to resist harmful substances when they are subjected to chloride penetration. The RCP of the G-RHA, U-RHA, G-BRHA and U-BRHA concrete was 29\%, 35\%, 59\% and $128 \%$ of the control concrete at 3 days, respectively. After 7 days, RCP value of the G-RHA, U-RHA and G-BRHA concrete was not much reduced and it exhibited a similar trend regarding the permeable porosity behaviour. At 28 days, the G-RHA, U-RHA, G-BRHA and U-BRHA had RCP values of $24 \%, 28 \%, 52 \%$ and $108 \%$ of the control concrete, respectively. The U-BRHA concrete showed poorer chloride resistance with RCP values of about $700^{\circ} \mathrm{C}$ but this value was in the range of that of a good concrete. The reduced coulomb values are in agreement with the results of other researchers for HSC [40, 41]. RHA reduced the value of chloride penetrability in concrete from a low to very low ratings from higher to lower replacement levels and the optimum replacement of cement with RHA for low coulomb value is $25 \%$ [40].

The high RCP value of the U-BRHA concrete indicated that the high LOI content and coarse particle of BRHA may contribute to the conductivity of the medium [4]. Incorporation of the G-BRHA as a mineral admixture improved the durability properties of HSC. Test results indicate that although the G-BRHA was not as effective as the U-RHA and G-RHA, using low energy to grind, preparing G-BRHA samples is relatively easy. It could significantly improve the durability of HSC. Therefore, the G-BRHA can be used as a mineral admixture in HSC, especially in rural areas.

\section{Conclusions}

In this study, black rice husk and grey RHA were ground using the LA abrasion machine. The average particle sizes of BHRA and RHA used were coarser than those previously reported $[9,11,13]$. Fresh, mechanical and durability properties of concrete containing 20\% unground and ground RHAs were investigated and compared to the properties of control concrete. Based on the test results of this study, the following conclusions can be drawn:

1. The surface areas of RHA or BRHA, not their carbon content, determined the dosages $\mathrm{Sp}$ required for similar workability compared to the control concrete.

2. Particles of unground and ground RHA showed synergies between pozzolanic and filler effects in concrete while ground BRHA acted dominantly as a filler effect. On the other side, unground BRHA exhibited a dilution effect.

3. The effect of grinding of RHA on the mechanical and durability properties of HSC with a $w / b$ of 0.46 is insignificant.

4. RHA can be used as partial cement replacement in the form of unground and ground ash due to the insignificant difference between unground and ground RHA in the mechanical and durability properties of HSC.

5. The compressive strength of concretes containing $20 \%$ ground BRHA as partial cement replacement attained the values equivalent to that of control concrete after 28 days. The results demonstrated that it is possible to develop acceptable ground BRHA concrete with comparable or better strength than that of the control concrete using lower cement content. Reducing usage of cement in concrete reduces environment pollution during the cement production.

6. After 56 days, the permeable porosity values of all RHA concretes are less than 4\%, except for unground BRHA concrete. This shows that unground BRHA cannot improve the microstructures of concrete as well as other types of RHA and it confirms that unground BRHA is not recommended for use in HPC of Grade 50.

7. The RCP values of concretes containing any type of RHA and ground BRHA were significantly less than that of the control concrete. This indicates that incorporation of RHA significantly improves the durability of HSC.

\section{Acknowledgement}

The authors would like to thank the Ministry of Science and Environment of Malaysia for awarding the IPPP Grant No. PS113/2008B and the UMRG Grant No. UMRG RP018/ 2012C to carry out the research on high strength rice husk ash concrete. The authors acknowledge the undergraduate students: Y W Yee and Y T Yeap, for helping in the 
concrete laboratory tests. The help of BASF (M) Sdn. Bhd. in supplying the superplasticizer is highly appreciated.

\section{References}

[1] Phan L T 2002 High-strength concrete at high temperature-an overview. In: Proceedings of the 6th International Symposium on Utilization of High Strength/High Performance Concrete

[2] FAO 2015 Rice market monitor, vol XVIII, issue 1

[3] Jauberthie R, Rendell F, Tamba S and Cisse I 2000 Origin of the pozzolanic effect of rice husks. Constr. Build. Mater. 14(8): 419-423

[4] Ganesan K, Rajagopal K and Thangavel K 2008 Rice husk ash blended cement: assessment of optimal level of replacement for strength and permeability properties of concrete. Constr. Build. Mater. 22(8): 1675-1683

[5] Chindaprasirt P, Homwuttiwong S and Jaturapitakkul C 2007 Strength and water permeability of concrete containing palm oil fuel ash and rice husk-bark ash. Constr. Build. Mater. 21(7): 1492-1499

[6] de Sensale G R 2006 Strength development of concrete with rice-husk ash. Cement Concr. Compos. 28(2): 158-160

[7] Nair D G, Jagadish K and Fraaij A 2006 Reactive pozzolanas from rice husk ash: an alternative to cement for rural housing. Cement Concr. Res. 36(6): 1062-1071

[8] Mahmud H B, Majuar E, Zain M F M, Rauf A R A and Beh K B 2003 Feasibility of using black rice husk to produce high strength concrete. In: Proceedings of the International Conference, The Concrete Institute of Australia (CIA), Brisbane, Australia, pp. 1239-1249

[9] Cordeiro G C, Toledo Filho R D and de Moraes Rego Fairbairn E 2009 Use of ultrafine rice husk ash with highcarbon content as pozzolan in high performance concrete. Mater. Struct. 42(7): 983-992

[10] Rêgo J, Nepomuceno A, Figueiredo E and Hasparyk N 2015 Microstructure of cement pastes with residual rice husk ash of low amorphous silica content. Constr. Build. Mater. 80: 56-68

[11] Chatveera B and Lertwattanaruk P 2011 Durability of conventional concretes containing black rice husk ash. J. Environ. Manage. 92(1): 59-66

[12] Chopra D, Siddique R and Kunal 2015 Strength, permeability and microstructure of self-compacting concrete containing rice husk ash. Biosyst. Eng. 130: 72-80

[13] Mahmud H 2010 Properties of high strength concrete incorporating black rice husk ash. In: Proceedings of the 2 nd ASEAN Civil Engineering Conference, Vientiane, Laos

[14] Ramadhansyah Putra J, Mahyun A W, Salwa M Z M, Bakar A, Megat Azmi M J and Mohd Haziman W I 2012 Thermal analysis and pozzolanic index of rice husk ash at different grinding time. Procedia Eng. 50: 101-109

[15] Krishnarao R, Subrahmanyam J and Kumar T J 2001 Studies on the formation of black particles in rice husk silica ash. $J$. Eur. Ceram. Soc. 21(1): 99-104

[16] Rukzon S, Chindaprasirt P and Mahachai R 2009 Effect of grinding on chemical and physical properties of rice husk ash. Int. J. Min. Metall. Mater. 16(2): 242-247

[17] Chopra S, Ahluwalia S and Laxmi S 1981 Technology and manufacture of rice husk masonry cement. In: Proceedings of the ESCAP/RCTT Third Workshop on Rice Husk Ash Cements, New Delhi

[18] Marsh B, Teychenne D, Franklin R and Erntroy H 1997 Design of normal concrete mixes. United Kingdom: Construction Research Communications Ltd

[19] Safiuddin M and Hearn N 2005 Comparison of ASTM saturation techniques for measuring the permeable porosity of concrete. Cement Concr. Res. 35(5): 1008-1013

[20] Shi C, Wu Y, Riefler C and Wang H 2005 Characteristics and pozzolanic reactivity of glass powders. Cement Concr. Res. 35(5): 987-993

[21] Habeeb G A and Mahmud H B 2010 Study on properties of rice husk ash and its use as cement replacement material. Mater. Res. 13(2): 185-190

[22] Gosalvitr P, Srinophakun P, Kanchanapiya P and Danwittayakul S 2015 The effects of particle size and content of rice husk ash from textile wastewater treatment on the properties of Portland cement-base solidification. In: Proceedings of the International Conference on Biological, Environment and Food Engineering (BEFE-2015), May 15-16

[23] Aitcin P C 2001 The ingredients of high-performance concrete. Concr. Int. 20-21

[24] Mindess S, Young F and Darwin D 2003 Concrete, 2nd ed. New Jersey, USA: Prentice-Hall

[25] Mahmud H B and Bahri S 2014 Mechanical properties of high strength high performance $100 \mathrm{MPa}$ concrete incorporating rice husk ash. In: Proceedings of the 8th International Conference on Engineering and Technology Research. Dubai, UAE: Novotel World Trade Centre

[26] Sua-iam G and Makul N 2013 Utilization of limestone powder to improve the properties of self-compacting concrete incorporating high volumes of untreated rice husk ash as fine aggregate. Constr. Build. Mater. 38: 455-464

[27] Hu J and Stroeven P 2004 Properties of the interfacial transition zone in model concrete. Interface Sci. 12(4): 389-397

[28] Tangpagasit J, Cheerarot R, Jaturapitakkul C and Kiattikomol K 2005 Packing effect and pozzolanic reaction of fly ash in mortar. Cement Concr. Res. 35(6): 1145-1151

[29] Heikal M and Aiad I 2008 Influence of delaying addition time of superplasticizers on chemical process and properties of cement pastes. Ceram. Silikaty 52(1): 8

[30] Tandırlı E, Akalın Ö and Arca E 2000 Effects of different superplasticizers on early strength of concrete. In: Proceedings of the Fifth CANMET/ACI International Conference on Durability of Concrete, Barcelona, Spain

[31] Scrivener K L, Crumbie A K and Laugesen P 2004 The interfacial transition zone (ITZ) between cement paste and aggregate in concrete. Interface Sci. 12(4): 411-421

[32] Chowdhury S, Maniar A and Suganya O 2015 Strength development in concrete with wood ash blended cement and use of soft computing models to predict strength parameters. J. Adv. Res. 6(6): 907-913

[33] Le Thanh Ham K S and Ludwig H M 2012 Synergistic effect of rice husk ash and fly ash on properties of self-compacting high performance concrete. In: Proceedings of Hipermat 2012. 3rd International Symposium on Ultra-High Performance Concrete (UHPC) and Nanotechnology for High Performance Construction Materials, Kassel University Press $\mathrm{GmbH}$

[34] Chindaprasirt P, Kanchanda P, Sathonsaowaphak A and Cao H 2007 Sulfate resistance of blended cements containing fly 
ash and rice husk ash. Constr. Build. Mater. 21(6): 1356-1361

[35] Hwang C L and Chandra S 1997 The use of rice husk ash in concrete. Norwich, NY: William Andrew Publishing/Noyes, pp. $184-234$

[36] Mehta P 1979 The chemistry and technology of cements made from rice husk ash. In: Proceedings of the UNIDO/ ESCAP/RCTT Workshop on Rice-Husk Ash Cement, Peshawar, Pakistan

[37] A.C. 3181995 Building code requirements for reinforced concrete. American Concrete Institute
[38] Erdem T K and Kirca Ö 2008 Use of binary and ternary blends in high strength concrete. Constr. Build. Mater. 22(7): 1477-1483

[39] Neville A M 2008 Properties of concrete, 14th ed. Malaysia: CTP-VVP

[40] Saraswathy V and Song H W 2007 Corrosion performance of rice husk ash blended concrete. Constr. Build. Mater. 21(8): 1779-1784

[41] Nehdi M, Duquette J and El Damatty A 2003 Performance of rice husk ash produced using a new technology as a mineral admixture in concrete. Cement Concr. Res. 33(8): 1203-1210 